\title{
Ruptured renal cell carcinoma in pregnancy: a rare case presentation
}

\section{Prameela RC*, Sasirekha R}

\author{
${ }^{1}$ Department of Obstetrics and Gynaecology, Mysore Medical College and Research Institute, Mysuru, Karnataka, \\ India \\ ${ }^{2}$ Department of Obstetrics and Gynaecology, JIPMER, Puducherry, India
}

Received: 09 March 2016

Accepted: 09 April 2016

\author{
*Correspondence: \\ Dr. Prameela RC, \\ E-mail: rcprameela@yahoo.com
}

Copyright: ( $)$ the author(s), publisher and licensee Medip Academy. This is an open-access article distributed under the terms of the Creative Commons Attribution Non-Commercial License, which permits unrestricted non-commercial use, distribution, and reproduction in any medium, provided the original work is properly cited.

\section{ABSTRACT}

Malignancy in pregnancy is rare. Carcinomas in pregnancy are mostly kidney cell mass. Renal cell carcinoma (RCC) is the commonest malignancy in pregnancy. Because of softness and increased vascularity, rupture of renal cell carcinoma is not uncommon. Here we are presenting a rare case of renal cell carcinoma in pregnancy with spontaneous rupture resulting in massive hemoperitoneum and serious outcome because of late presentation renal cell carcinoma seldom ruptures. A 26 year old woman G2P1L1 with term pregnancy was referred to hospital 80kms away from periphery with non-progression of labour. There was antenatal record suggesting hypertensive disorder of pregnancy in second trimester. On examination, patient was in hypovolemic shock with profuse distension of abdomen. Diagnosis of abruption grade 3 or rupture uterus was made and immediate laparotomy was done. On opening the abdomen, there was hemoperitoneum but uterus was intact. Emergency LSCS done extracted a stillborn baby. There were no retro placental clots also. There was lot of necrotic tissue in the abdomen and there was a tumour arising from lower pole of left kidney which had invaded the renal vessels and had ruptured. Peripartum hysterectomy and left nephrectomy was done. Women did not respond to treatment and died. The objective of presenting this case is the dilemmas faced by the obstetrician in case of shock in 2nd stage of labour. Simple diagnostic tool like renal ultrasound will help to detect at an early stage which could improve the outcome. All cases of hypertensive disorders of pregnancy should be investigated for secondary causes of hypertension. Abdominal USG must be done for all cases of hypertensive disorders of pregnancy in 2nd trimester. Prompt diagnosis and early treatment is the key in management of such condition in pregnancy.

Keywords: Renal cell carcinoma, Pregnancy, Rupture

\section{INTRODUCTION}

Malignancy is a rare occurrence in pregnancy. It is uncommon to see renal cell carcinoma in women of reproductive age group. In less than $0.1 \%$ of pregnancy are complicated by any type of neoplasm and only $0.0013 \%$ (13 in 1000000 pregnancy) by urinary cancer. ${ }^{1,2}$

Renal cell carcinoma is the most common renal malignancy accounting for almost $90-95 \%$ of all primary renal neoplasms ${ }^{3}$

Only 70 cases have been reported in literature. This is the first case in our institute. The incidence may be higher now, may be due to increased maternal age and improved imaging modalities. In pregnancy, foetal anomaly scan is done at 20 weeks and focuses on pelvic region. But a full abdominal USG during pregnancy allows early diagnosis of malignancy and wellbeing of mother and foetus. Abdominal USG in pregnancy is a must. Malignancy in pregnancy sometime presents similar to common symptoms of pregnancy and possibility of malignancy may not be kept in mind and hence difficult to identify until advanced stage of pregnancy. ${ }^{4}$

Multidisciplinary approach is mandatory in the diagnosis and management of renal cell carcinoma in pregnancy. 
Since radical surgery is the treatment of choice in most stages, the wellbeing of pregnant women should be the first priority. Early surgery improves the outcome.

\section{CASE REPORT}

A 26 year old woman G2P1L1with term pregnancy was referred to Cheluvamba Hospital attached to our institution Mysore Medical College \&Research Institute. She was referred for non-progression of labour from tribal area $80 \mathrm{kms}$ away.

Antenatal records were scrutinised. There was antenatal record of hypertension suggesting Hypertensive Disorders in Pregnancy in second trimester; all others were with in normal limits. On examination, patient was in hypovolemic shock with huge distension of abdomen. Uterus and foetal parts were not made out and foetal heart sound was not localised. On pelvic examination, patient was in $2^{\text {nd }}$ stage of labour with vertex at -1 station. She presented to us in second stage of labour in shock. Diagnosis of grade 3 abruption placenta or rupture uterus was made.

Immediate laparotomy was done. On opening the abdomen, there was hemoperitoneum. But uterus was intact. At that time, source of bleeding could not be made out and proceeded with LSCS, extracted a stillborn female baby and there was no retro placental clots. Uterus was closed. As the cause for bleeding was being searched, a lot of necrotic tissue was obtained from the peritoneal cavity (Figure 1).

Meanwhile, peripartum hysterectomy was also done fearing atonic PPH. With the help of surgical team we could identify the origin of bleeding and tumour. There was a tumour arising from the lower pole of left kidney. Tumour had invaded the renal vessels and ruptured (Figure 2). Left nephrectomy was done (Figure 3). In spite of resuscitating with few bottles of blood, patient did not survive.

Histopathological examination from kidney tissue showed papillary carcinoma with numerous psomama bodies with areas of clear cell changes. Tumour was circumscribed but breached at many places.

\section{DISCUSSION}

Renal cell carcinoma represents $3 \%$ in adults. Commonest urological malignancy in pregnancy is renal cell carcinoma. Common in older patients between 50-70 years peak after $5^{\text {th }}$ decade of life. ${ }^{4}$ RCC in pregnancy presents with classical triad of haematuria and flank mass, flank pain. Haematuria is reported less commonly. The flank mass, is difficult to identify by abdominal examination by the obscuring of field by gravid uterus. Flank pain is the $2^{\text {nd }}$ most frequent presentation, may sometimes be the only presenting symptom.

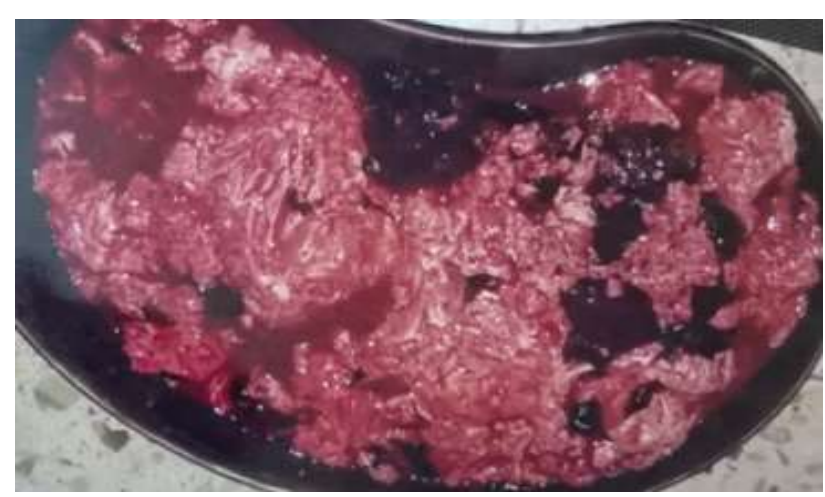

Figure 1: Necrotic mass.

In non-pregnant population, diagnosis of RCC, symptoms are suggestive of late disease. Pregnancy and cancers are the only 2 biological conditions where antigenic tissue is tolerated by a normally functioning immune system. ${ }^{4} \mathrm{As}$ in most cases RCC the biological behaviour of RCC is not influenced by pregnancy.

Some genetic translocations, gene Xp 11;2 are associated with aggressive renal tumour.

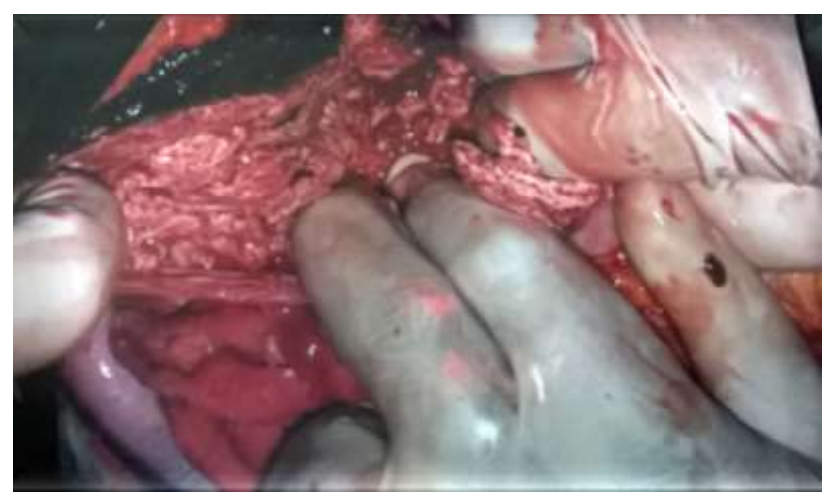

Figure 2: Mass eroding renal vein.

Diagnosis of RCC requires special investigations in pregnancy. Urine should be sent for cytological analysis's abdomen is non-invasive modality which has $85 \%$ sensitivity to that of IVP and CT. It is the preferred diagnostic modality. USG has no radiation risk, it can pick a mass of size $2 \times 3 \mathrm{~cm}$ but it is operator dependent and diagnosis is sub optimal.

IVP and CT are the imaging modalities of choice for renal malignancies. ${ }^{1}$ MRI is the choice of investigation in cases of malignancy in pregnancy as the contrast used does not pass through placenta. Radionucleotide scans have been used to assess the contralateral kidney and intrinsic activity. Doppler assessment is also done. ${ }^{1}$ Stiocessan concludes to use plasma rennin level as a screening test in young hypertensive pregnant patients to suspect kidney cancer.

Hypertension as a real cancer marker can draw the attention upon a RCC diagnosis, not being interpreted only as a hypertension in PE cases. 
Treatment of RCC is surgical resection of tumour. It needs multidisciplinary approach.

Timing of surgery is controversial. It depends on the trimester at which it's diagnosed; stage of the disease, malignancy, health of the mother and wellbeing of the foetus. Mother's choice is always important and respected.

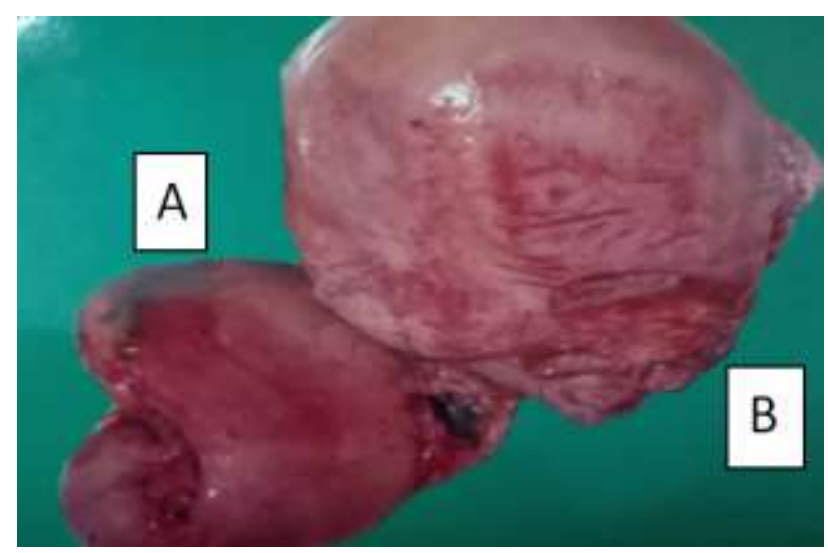

Figure 3: Nephrectomy specimen along with uterus. A; Kidney, B; uterus.

Renal neoplasm is slow growing and doubling time is 500 days. $^{5}$ If diagnosed late in pregnancy it is reasonable to wait for delivery. $2^{\text {nd }}$ trimester surgeries are always optimal. If found in $1^{\text {st }}$ trimester it is advisable to wait till $2^{\text {nd }}$ trimester. A solid mass needs immediate surgery.

Spontaneous rupture of primary RCC seldom occurs. ${ }^{6}$ Spontaneous rupture occurred in only 1 case, $0.3 \%$ of 309 cases and in one case $0.6 \%$ of 166 cases by Skinner et al. Akitosh et al reported 2 cases of rupture who were being treated for end stage disease. ${ }^{6}$ Perioperative diagnosis is very difficult.

No correlation reported between tumour size and frequency of rupture. ${ }^{7}$ Rupture of the mass may be due to extension of the mass to the renal vein, causing elevation in venous pressure secondary to tumour emboli or direct invasion to renal capsule.

In this presenting case, signs of hypertensive disorders in pregnancy (HDP) were present in second trimester. If this case was evaluated not merely as HDP but for secondary hypertension, we could have diagnosed renal cell mass in early stages. Non-invasive abdominal USG was the simplest investigation. The presenting sign of acute haemorrhage was due to the direct extension of mass to the renal vein causing high pressure secondary to tumour emboli. The labour events might have triggered the occurrence. As this pregnant women came in late stages of labour and in haemorrhagic shock, without any previous evaluation the outcome was not good.

\section{CONCLUSION}

All cases of hypertensive disorders in pregnancy should be investigated for secondary causes of hypertension. Abdominal USG must be done for all cases of hypertensive disorders in Pregnancy in 2nd trimester. Even though there are more benign causes for haematuria and hypertension during pregnancy such persistent symptoms should be evaluated for rare causes also. With increasing usage of USG in obstetrics, such conditions should not be missed. Because renal cell carcinoma in pregnancy is potentially curable with prompt diagnosis and management. Awareness of rare events should always be kept in mind.

\section{ACKNOWLEDGEMENTS}

We acknowledge the help extended by the family members of the women for giving consent to publish the case report. We also acknowledge the guidance extended by Prof H C Lokeshchandra.

\section{Funding: No funding sources Conflict of interest: None declared Ethical approval: Not required}

\section{REFERENCES}

1. Stoicescu M. Kidney Tumor in Pregnancy. J Nephrol Ther. 2013;3:138.

2. Tiang KW, Ng KL, Vega-Vega A, Wood S. Rapidly enlarging renal tumor during pregnancy: diagnostic and management dilemma, Journal of Kidney Cancer and VHL. 2014;1(1):12-6.

3. Cancer Facts and Figures 2015. American Cancer Society. Available at http://www.cancer.org/acs/ groups/content/@editorial/documents/document/acsp c-044552.pdf. Accessed: September 29, 2015.

4. Loughlin KR. The management of urological malignancies during pregnancy British Journal of Urology. 1995:639-44.

5. Bettez M, Carmel M, Temmar R, Côté AM, Sauvé $\mathrm{N}$, Asselah J. Fatal fast-growing renal cell carcinoma during pregnancy. J Obstet Gynaecol Can. 2011;33(3):258-61.

6. Kobayashi A, Yamaguchi T, Ishihara T, Tadenuma $\mathrm{H}$, Nakamura K, Ohshima T. Spontaneous rupture of pancreatic metastasis from renal cell carcinoma. Japanese Journal of Clinical Oncology. 2004;34(11):696-9.

7. Skinner DG, Colvin RB, Vermillion CD, Pfister RC, Leadbetter WF. Diagnosis and management of renal cell carcinoma. A clinical and pathologic study of 309 cases. Cancer. 1971;28(5):1165-77.

Cite this article as: Prameela RC, Sasirekha R. Ruptured renal cell carcinoma in pregnancy: a rare case presentation. Int J Reprod Contracept Obstet Gynecol 2016;5:1677-9. 